Niall Ó DOCHARTAIG, Katy HAYWARD and Elizabeth

MEEHAN (eds), Dynamics of Political Change in Ireland: Making and Breaking a Divided Ireland, Milton Park/ NewYork, Routledge, 2016

\title{
Philippe Cauvet
}

\section{(2) OpenEdition \\ 1 Journals}

\section{Édition électronique}

URL : http://journals.openedition.org/etudesirlandaises/5400

DOI : 10.4000/etudesirlandaises.5400

ISSN : 2259-8863

\section{Éditeur}

Presses universitaires de Caen

\section{Édition imprimée}

Date de publication : 29 novembre 2017

Pagination : 161-162

ISBN : 978-2-7535-7388-8

ISSN : 0183-973X

\section{Référence électronique}

Philippe Cauvet, « Niall Ó Dochartaig, Katy Harward and Elizabeth Meenan (eds), Dynamics of Political Change in Ireland: Making and Breaking a Divided Ireland, Milton Park/NewYork, Routledge, 2016 », Études irlandaises [En ligne], 42-2 | 2017, mis en ligne le 29 novembre 2017, consulté le 24 septembre 2020. URL : http://journals.openedition.org/etudesirlandaises/5400 ; DOI : https://doi.org/10.4000/ etudesirlandaises. 5400

\section{(c) (1) (-)}

Études irlandaises est mise à disposition selon les termes de la Licence Creative Commons Attribution - Pas d'Utilisation Commerciale - Partage dans les Mêmes Conditions 4.0 International. 
lise jamais le texte comme prétexte à un commentaire sociologique mais sait au contraire exalter les qualités esthétiques des œuvres considérées.

Sylvie Mıкоwsкi

Niall Ó Dochartaig, Katy HaYward and Elizabeth Meehan (eds), Dynamics of Political Change in Ireland: Making and Breaking a Divided Ireland, Milton Park/NewYork, Routledge, 2016, 288 p., ISBN 978-1-1381-9600-1 (hardcover), £110.00, ISBN 978-1-3156-3806-5 (ebook), £27.99.

Cette collection d'articles, publiée sous la co-direction de Niall Ó Dochartaigh, Katy Hayward et Elizabeth Meehan et préfacée par Brendan O'Leary, contient 13 contributions rassemblées en trois chapitres intitulés successivement Contexts, Competition et Complexity. Cette publication est une forme d'hommage à John Coakley dont Brendan O'Leary fait remarquer, à juste titre, la qualité du travail scientifique qu'il a réalisé au cours de sa riche carrière, à Dublin, à Queen's University Belfast mais aussi à l'échelle internationale - Etudes Irlandaises peut d'ailleurs s'enorgueillir d'avoir publié plusieurs de ses articles.

Dès l'introduction, les trois co-directeurs définissent l'objectif ambitieux de l'ouvrage : il s'agit de voir en quoi les interactions entre d'une part, les partis politiques, la société et les idéologies et d'autre part, les structures institutionnelles étatiques et internationales, ont contribué à façonner mais aussi à déconstruire l'espace politique irlandais depuis la partition. Ils affirment aussi que pour répondre à cette question de manière complète, il est impossible d'ignorer les menaces que le résultat du référendum de juin 2016, favorable au Brexit, fait peser sur les fragiles équilibres politiques, sociaux, économiques et culturels qui avaient été trouvés en Irlande depuis 1998. Les "dynamiques du changement politique en Irlande " sont clairement envisagées dans un cadre pluridisciplinaire (histoire, science politique, économie, sociologie...) et pluridimensionnel (dimensions irlandaises, anglo-irlandaises, européennes et mondiales). Naturellement, avec une telle ambition, la question majeure (même si d'autres, comme celle des genres par exemple, sont évoquées par Y. Galligan et M. Hoewer) est celle de l'évolution des nationalismes, des nations et des États, britannique et irlandais.

Le travail accompli dans cet ouvrage est remarquable et doit, à n'en pas douter, faire plaisir à John Coakley. Il pourra y voir très visiblement le signe de sa grande influence scientifique mais c'est pour deux autres raisons principales qu'on imagine sa satisfaction et celle des autres lecteurs de ce livre. Premièrement, les contributions réunies permettent de comprendre la complexité et la multiplicité des formes du 
changement politique en Irlande et la façon dont ces changements sont liés à des contextes extérieurs à l'Irlande elle-même. C'est l'un des rares ouvrages analysant la vie politique en Irlande qui ne fasse pas le choix d'un découpage thématique, spatial ou chronologique réducteur. La contribution de Ó Dochartaigh sur la composante territoriale de l'Etat et de l'identité nationale est parfaitement symptomatique de cette démarche délibérément intégrée qui se rapproche de la géopolitique. Deuxièmement, ce qui rend cette collection d'articles encore plus pertinente, c'est sa capacité à combiner deux exigences scientifiques pourtant souvent contradictoires : la profondeur historique (voir les contributions de Laffan, Gallagher, Tonge ou Ruane par exemple) et l'analyse de situations plus récentes (McLoughlin, Arthur, Todd), voire immédiates (Hayward et Howard sur les dynamiques de fermeture culturelle en cours en République d'Irlande et au Royaume Uni ou Andy Pollack sur l'extrême fragilité actuelle de la coopération Nord-Sud).

Il ressort de l'ensemble de ces travaux l'idée que le changement politique est consubstantiel à la vie politique sur l'île d'Irlande et que l'accord trouvé en 1998, même s'il résulte de mutations profondes et multiples, est éminemment fragile et contingent, comme l'avaient été avant lui ceux de 1921/1925, de 1973 ou de 1985. Finalement, si un tel constat s'impose à la lecture de cet ouvrage, c'est que la solution adoptée en 1998 ne marquait pas une véritable transformation de la situation mais plus une forme de gestion du conflit. Ce qu'O'Leary présente, dans la préface, comme la preuve de la force et de la flexibilité de l'Accord de 1998, à savoir le passage dans l'opposition du SDLP et du UUP, n'est-il pas aussi le signe de sa faiblesse? Si ces deux partis nord-irlandais, les plus modérés dans leur camp, ont ressenti le besoin de ne pas rentrer dans le gouvernement nord-irlandais, c'est précisément parce que l'action gouvernementale dans un système consociationnel ne permet pas de transformer la société nord-irlandaise ni de faire de l'Irlande du Nord un espace politique et culturel partagé. Dans un contexte où les Irlandais du Sud et les Anglais montrent une forte tendance au repli culturel (voir la contribution de Hayward et Howard sur le référendum de 2004 en Irlande et celui de 2016 au Royaume-Uni), quel est l'avenir d'une Irlande du Nord où les modérés, dans les deux camps, sont de plus en plus minoritaires? Aussi remarquables qu'aient pu être l'Accord de 1998 et sa mise en œuvre, ce livre ambitieux et les circonstances particulières dans lesquelles il a été produit (référendum sur le Brexit, absence de gouvernement en Irlande du Nord depuis plusieurs mois, pacte parlementaire entre DUP et Parti conservateur à la Chambre des Communes) nous appellent aussi à prendre conscience du chemin qu'il reste encore à parcourir pour que l'île d'Irlande et l'Irlande du Nord se transforment et deviennent, réellement, des espaces politiques et culturels partagés. 